\title{
The synthesis of a unified pedagogy for the design and evaluation of e-learning software for high-school computing
}

\author{
Peter Yiatrou \\ University of Central \\ Lancashire. Fylde Road, \\ Preston, Lancashire PR1 \\ 2HE, United Kingdom \\ Email: pyiatrou@uclan.ac.uk
}

\author{
Irene Polycarpou \\ University of Central \\ Lancashire Cyprus. 12 - 14 \\ University Avenue Pyla 7080 \\ Larnaka, Cyprus \\ Email: \\ ipolycarpou@uclan.ac.uk
}

\author{
Janet C Read \\ University of Central \\ Lancashire. Fylde Road, \\ Preston, Lancashire PR1 \\ 2HE, United Kingdom \\ Email: jcread@uclan.ac.uk
}

\author{
Maria Zeniou \\ University of Central \\ Lancashire Cyprus. 12 - 14 \\ University Avenue Pyla \\ 7080 Larnaka, Cyprus \\ Email: \\ mzeniou1@uclan.ac.uk
}

\begin{abstract}
This study develops a unified pedagogy for the design and evaluation of e-learning software for high-school Computer Science. In accordance with the pedagogy, prototype e-learning software was developed for use in student instruction and independent learning. The pedagogy was iteratively refined based on the evaluation of teachers and education experts and the resulting e-learning software was developed considering student feedback. The problem domain focuses on the UK's recent shift in educational emphasis towards Computer Science GCSEs; however, the findings are broadly transferable to other developed nations. The pedagogy synthesizes the following learning theories: Constructivism, Social Constructivism, Connectivism, Cognitive Load, ARCS and VARK learning styles, these were in turn distilled into 31 heuristics. The research is broken into three phases, the first two phases are discussed in this paper; Phase 1 is the Initial Pedagogical Strategy and Prototype, Phase 2 is the Elaboration via Action Research.
\end{abstract}

\section{INTRODUCTION}

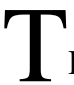
HERE is a well-publicized body of inquiry, consisting of various reports, analysis and political rhetoric that assert that computing education in the UK has been struggling [9], [11], [22]. This concern led to the programme of study for Information and Communication Technology (ICT) being temporarily dis-applied while new initiatives introduced an arguably more academically rigorous Computer Science GCSE [8].

The prevalence and ubiquitous nature of ICT in developed countries and its impact on recent generations is well documented [13]. Digital technology is shown to be a fundamental part of the fabric of society in developed countries such as the UK [9], [15], [18]. These findings arguably make the need for computing education all the more important, and in support of computing education it is postulated that e-learning software can offer learning benefits in the form of a media rich interactive environment that is engaging and can promote active learning [7].

The objective of the research presented in this paper is to study and synthesize leading learning theories into a single

This work was not supported by any organization unified e-learning pedagogy that will support high school computing, and in particular, the new Computer Science GCSEs. This pedagogy will be embodied in an e-learning software prototype and both will be evaluated to identify their impact on student learning and engagement.

\section{II.QUALITY E-LEARNING SOFTWARE}

Although e-learning software has become mainstream, one of the main concerns still remains that what is delivered often falls short [1], [6]. Content quality, pedagogical usability, instructional design and a lack of alignment with education needs and standards remain a concern in existing e-learning software [6], [12], [20].

This research aims to support increased use of e-learning in high-school Computer Science, and to safeguard the pedagogical quality of the e-learning software, by defining a comprehensive set of pedagogical heuristics to guide teachers in designing and/or evaluating e-learning software for use in teaching. Therefore, in the context of this research, quality focuses on the standard and degree of excellence of the pedagogy underpinning the learning process.

\section{LEARNING THEORIES}

One approach to ensure the pedagogical quality of elearning software is to ground it in established learning theories. There is a significant body of research into learning theories, e-learning and Science, Technology, Engineering and Mathematics (STEM) education, but this is somewhat overwhelming; there are complementary and competing learning theories and varied perspectives on how to best implement these theories in technology [14], [25].

Illeris [14] proposes that since learning is so complicated, any "analyses, programmes and discussions of learning must consider the whole field if they are to be adequate and reliable"(p.18). It is for this reason that this research synthesizes this overwhelming body of knowledge into an accessible set of pedagogical heuristics. The learning theories considered include Constructivism [4], Social Constructivism [19], [24], Connectivism [3], Cognitive Load [7], [23], ARCS [16], [17] and VARK learning styles classification [10]. These theories were selected primarily 
due to their maturity and the availability of research that discusses them, their effective implementation, and the evidence of their positive affect on learning and motivation. A final consideration was to include theories that relate to technology and our current digital society.

\section{RESEARCH METHODOLOGY}

The research study that is presented in part in this paper is divided into three phases (Refer to Fig. 1) and each phase uses a mixed methods approach, but with a different qualitative-quantitative mix. Overall, the phased approach utilizes an exploratory mixed methods design in which Phase 1 and 2 use primarily qualitative data from students, teachers and education experts to synthesize a set of pedagogical heuristics. The rationale for this research design is to initially work in depth using significant literature review and iterative Action Research cycles to gradually refine the heuristics and e-learning test tool.

Phase 3, although not discussed in this paper, will have a quantitative priority and a larger student sample in order to generalize the findings to the wider student population. The aim will be to measure whether there are improved assessment results using e-learning software that adheres to the pedagogical heuristics synthesized in this research.

\section{A. Phase 1: Initial Pedagogical Strategy and Prototype}

The primary objective of Phase 1 was to set a strong foundation for the research study; this was achieved in terms of:

1. Piloting the research methods and protocol,

2. Developing the first draft of the e-learning pedagogical heuristics,

3. Developing a working e-learning software prototype for the topics of Algorithms and Computational Thinking that was in turn used for evaluation purposes.

This supported the early identification of shortcomings in the research methods and protocol, and in the design and development processes; but most importantly, it allowed early feedback on the pedagogy and e-learning software.

The first step was to undertake a comprehensive literature review resulting in the first draft of the e-learning pedagogical heuristics for GCSE Computing.

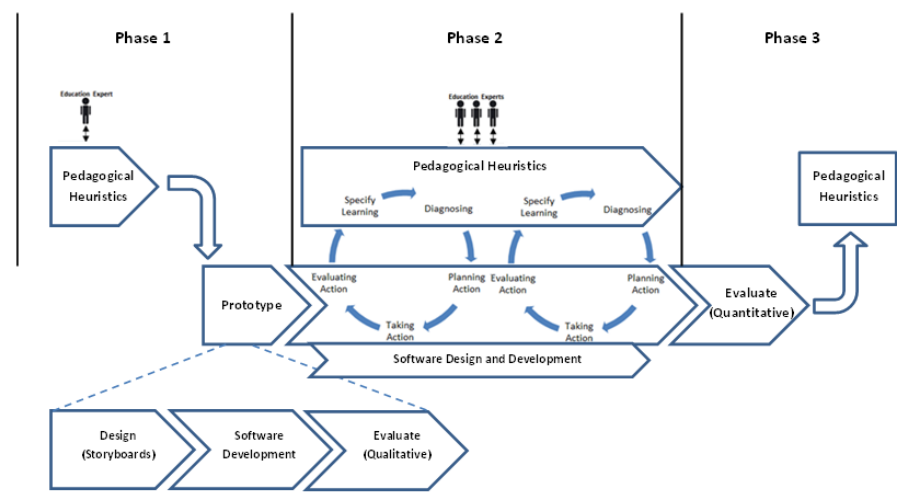

Fig. 1 The three phases of research.
An experienced GCSE teacher and five education experts then evaluated the pedagogy and provided constructive feedback and validation of the appropriateness of the heuristics for Computer Science for the GCSE age group. This feedback was analyzed and incorporated into the research prior to Phase 2-Cycle 1 .

As a proof of concept, a prototype e-learning software was developed according to the e-learning pedagogical heuristics. Eight GCSE ICT students were recruited from a local high school and observed using the e-learning software. Prior to the observation study, an online VARK questionnaire was administered to participants to collect their learning style preferences. Additionally, after the observation study an online survey was administered to collect participants' feedback on their experience of using the e-learning software. This survey also included John Keller's Instructional Materials Motivation Survey (IMMS), which measures student motivation according to the ARCS motivation model [16]. Subsequently, a focus group was held in which the participants had a facilitated discussion where they elaborated on the key themes identified in the observation study and the survey results.

The findings from the observation study, VARK questionnaire, student survey and focus group were examined holistically to understand whether the different research strands converged or diverged, to identify areas requiring further investigation, and to inform the development of the pedagogical heuristics and the e-learning software for Phase 2-Cycle 1. The findings are predominantly qualitative in nature; have a small sample size and are a collection of open and ordinal data (Likert and Ranking). Descriptive statistics gave basic quantification of results and are followed by textual descriptions that link to open responses from either the questionnaire or focus group and interpret the result findings.

\section{B. Phase 2: Elaboration via Action Research}

The purpose of Phase 2 was to further refine and elaborate the e-learning pedagogical heuristics and software via an Action Research methodology. An Action Research approach was chosen since it links theory and practice, achieving both practical and research objectives. The practical focus lies in the iterative development of the elearning software and the research focus on the elaboration, evaluation and validation of the e-learning pedagogical heuristics. Susman and Evered [21] detail a five phase cyclical process, which forms the basis of the action research cycle used in this research. The five phases are diagnosing, action planning, action taking, evaluating and specify learning; these are outlined in Fig. 2.

Two cycles of evaluation and update were included in Phase 2. Phase 2-Cycle 1 study participants were six year 5 high school students (2nd year of the GCSE) and three year 4 high school students (1st year of the GCSE). The year 5 students also participated in Phase 1 and have worked with 
the previous version of the e-learning software. With each cycle of Action Research, the e-learning pedagogical heuristics were updated based on the evaluation of teachers, education experts and ongoing literature review. Then, aspects of the pedagogy were represented in the e-learning software for evaluation purposes.

As with Phase 1, the student feedback on the e-learning software was collected via a combination of direct observation of software usage, online questionnaire and associated focus groups. Again, aligned with Phase 1, these findings were represented with descriptive statistics and contextualized with text description and links to open responses. These findings are examined holistically and merged with the feedback from education experts in order to inform the next cycle of action research.

\section{V.DEVElopment of PEDAGOGICAL HeURISTICS}

The pedagogical heuristics originally developed in Phase 1 have been iteratively refined and evaluated by two teachers and five education experts in Phase 1 and Phase 2-Cycle 1. Both teachers teach GCSE Computer Science or ICT; one teacher had five years of experience at the time of the study, the other less than one year of experience. The education experts were university academics in the fields of Child Computing Interaction, Computer Science, Education and Educational Media.

In Phase 1-Cycle 1 there were 31 e-learning heuristics defined. The evaluation findings in Phase 2-Cycle 1 indicate that the heuristics have a comprehensive pedagogical coverage, are appropriate for Computer Science, and are overall appropriate for the GCSE age group (15 and 16 year olds). Whilst the heuristics themselves have received positive feedback, the pedagogy document requires further work in Phase 2-Cycle 2 to reduce the document size, rationalize the heuristics and make the pedagogy more appropriate for its intended usage and audience.

\section{RESUlts}

Research findings from Phase 1 and Phase 2-Cycle 1 have informed the e-learning pedagogical heuristics and the elearning prototype; however, this section discusses only the most significant findings, such as multimodal learning, active learning, authenticity vs. cognitive load, moderation in the heuristics, collaborative learning and learner motivation. Phase 2-Cycle 1 gave some initial encouraging findings since all nine participants agreed or strongly agreed that the elearning software was easy to use. All participants either agreed or strongly agreed that the learning content in the elearning software was represented in a clear and understandable way. Furthermore, none of the eight respondents reported that they supplemented, or needed to supplement, the learning material in the e-learning software with further textbook reading. This is self-reported feedback and does not equate with learning, but it does give a positive

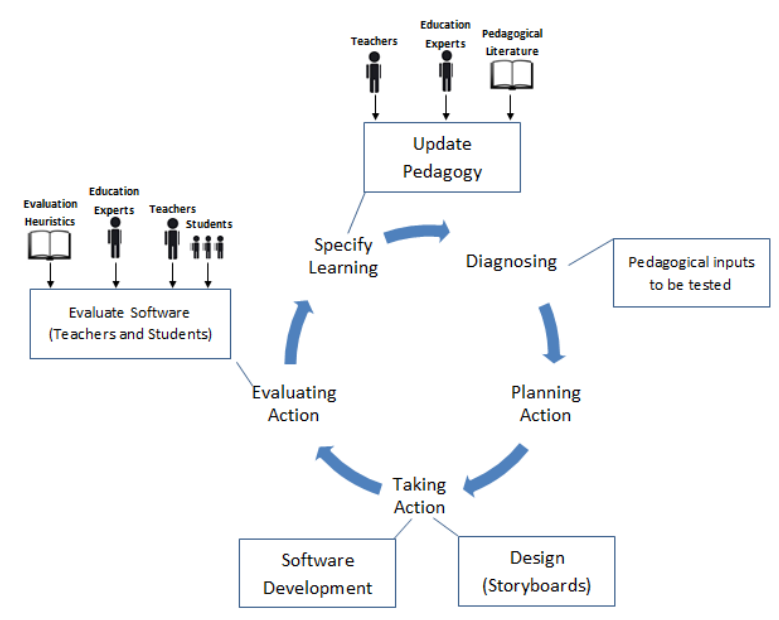

Fig. 2 Action Research Cycle

indicator of the value of the pedagogical heuristics.

\section{A. Multimodal Learning}

Multi-modal learning was implemented in the software by representing educational material through combinations of text, audio, video, diagrams, pictures, animations and activities. The findings from Phase 1 and Phase 2-Cycle 1 support the multi-modal strategy outlined in the pedagogy. The combined VARK modal preferences of the student participants in both phases show a relative balance across the four modalities. This is further supported by the feedback in Phase 2, where four students agreed and four students strongly agreed with the statement "The approach of using varying methods to represent the same educational concepts helped my understanding." Speaking on this point one student summarized that: "I really liked the short videos, I think the pictures were actually really good, the text was also decent... " [Student 19]

The multimodal approach is also given additional credibility since in Phase 1 the instructional designer for the e-learning software had a dominant Read/Write modal preference, which was left unmanaged and resulted in elearning software with a heavy text bias. This led to a clear negative reaction in the Phase 1 student feedback. In Phase 2-Cycle 1, knowing this bias, the instructional designer took appropriate mitigation steps. This led to an improved response from the student participants in Phase 2-Cycle 1.

\section{B. Active Learning}

In support of the constructivist principle of active learning, the pedagogy proposes a significant focus on activities, problem solving and kinesthetic learning. This form of learning was well received by students; all nine students agreed or strongly agreed that the activity-based parts (problem solving, games, simulations, assessments and quizzes) of the e-learning software helped them to understand the subject matter. In addition, all nine students agreed or strongly agreed that the activity-based parts of the e-learning software were engaging. 


\section{Authentic learning vs reducing cognitive load}

In schools, there is a tension between preparing students for assessments and the responsibility to develop wellrounded individuals who can think beyond exams. This pedagogical tension is also reflected in the e-learning pedagogy. For example, in order to reduce cognitive load, all learning material that does not directly contribute to learning outcomes should be reduced or removed; but this in turn, can weaken the authentic learning also proposed in the pedagogy. The tension between authenticity and cognitive load was discussed in both focus groups; the majority of students felt that authentic learning material that may not be directly examinable should not be sacrificed in favor of reducing cognitive load. Speaking on this point one student summarized that: "It might not be in the exam but it really broadens your perspective, especially in giving you examples of real life applications. " [Student 23]

The important factor was that each student needed to use their judgment to decide whether they would focus on such supplementary learning content. In the focus groups, it was agreed that in order to support this decision making process, such learning material would be clearly marked with a visual marker to reflect that it is supplementary information.

\section{D.Moderation and balance in Heuristics}

Taken at their extremes, learning theories such as Constructivism and Connectivism postulate some radical positions; these include learners being free to identify their own learning needs as they materialize, being free to support those learning needs by choosing their own learning (nodes) from the learning network and being free to construct their own understanding. In contrast, the preliminary findings of this research support a moderate balanced set of heuristics. The findings from Phase 1 and Phase 2-Cycle 1 show that the students value a degree of freedom, especially in learning activities, but that freedom needs to be bounded within a structured environment.

In Phase 2 Cycle 1, five students agreed and four students strongly agreed with the statement "It is easy to use the navigation and program controls of the e-learning software." This strengthened the Phase 1 results and gave positive support for heuristics related to restricted navigational control. During both focus groups, the students clearly voiced support for the restricted navigation approach.

Furthermore, the results of the survey instrument suggest that the students are fully aware of the value of using the Web to support their subject learning, but the majority still prefer the guidance of the e-learning software to support their learning. This aligns with the moderate Connectivist approach suggested in the pedagogy in which the e-learning software becomes the hub that suggests (links to) other learning resources that are known to be reliable. As in Phase 1, the e-learning software was perceived to be comprehensive and the students preferred the structure of having one place to learn from, avoiding the wasted time in searching the Web and evaluating whether the information they find is correct. Almost all student feedback was aligned with the following comment: "The E-Learning software has activities and features that are much more engaging than looking up information on the Web. The Web sometimes contains sites with wrong information, so the E-Learning software would be a much more reliable and easy source of information." [Student 14]

The Phase 2-Cycle 1 focus groups also revealed some unexpected feedback. Although, the e-learning software had an implicit structure and grouping of learning content, a significant portion of the students expressed the opinion that they would like explicit sections to be introduced. These sections were suggested to mimic a traditional chapter format, with the chapter learning objectives, learning material, review questions and finally a learning summary.

\section{E. Collaboration}

The research study has shown conflicting findings in relation to collaborative learning. Based on a student ranking of ten learning object types collaborative learning is ranked lowly in eighth place. Furthermore, only three from eight students agreed or strongly agreed that collaborative activities helped them understand the subject matter. However, a follow up question in the survey instrument and further discussion in the focus groups offered a different context. The students were asked to describe briefly, whether the collaborative activities gave them any learning or motivational benefits and what those benefits were. "The collaborative activities gave me and my partner the opportunity to help each other understand the questions we had. One could answer the questions of the other, which was really helpful in order to complete our task.'[Student 14]

The positive responses where reiterated and elaborated during the focus groups; however, one critical factor was also expressed. The respondents clarified that technology enhanced collaborative activities are artificial in a classroom context and much more suited for homework. In the context of this study, the majority of time spent using the e-learning software and the collaborative learning environment (CLE) was in class hence did not feel natural to the students. What was tentatively postulated in Phase 1 was more clearly established in Phase 2-Cycle 1; the experiment design had influenced the research findings. To naturally reflect a collaborative learning context requires a longer duration in which the students have weeks to review, respond and interact. However, the abiding conclusion from Phase 2Cycle 1 was that despite the mixed feedback, overall, the students saw good potential for collaborative learning in spite of an initial learning curve.

\section{F. Motivation}

One of the key objectives of the e-learning pedagogy is to improve learning motivation; a number of heuristics specifically focus on student motivation and others offer supplementary motivational benefits. Phase 2-Cycle 1 
findings are therefore broadly positive that six from nine respondents reported that the e-learning software increased their overall enthusiasm and interest in computing.

In relation to the ARCS motivation model, which focuses on Attention, Relevance, Confidence and Satisfaction, the results from the IMMS survey gave further positive indicators for student motivation. The results range between 3.52 and 3.76 on a continuum between Moderately True (3) to Mostly True (4), the maximum on this scale being Very True (5).

\section{CONCLUSION AND FURTHER WORK}

In this paper we have presented early research that suggests that e-learning can offer educational benefit to high school Computer Science. This educational benefit is realized and maximized by ensuring that the e-learning is underpinned by an appropriate set of e-learning pedagogical heuristics. The qualitative research described here offers support for a number of the heuristics developed in the pedagogy and offer further direction on areas to further refine in Phase 2-Cycle 2.

Although the focus of this research is primarily the UK there are various international comparisons [2], [5], [22] that show that the concerns and challenges outlined in the UK are common to a number of countries. The US, New Zealand, Israel, Germany and India are all in varying stage of similar initiatives to give greater prominence to the high-school computing curriculum. It follows that the findings of this research will be broadly transferable to such initiative in other nations.

The progress so far in Phase 1 and Phase 2 of the presented research, give a sound indication that the developed heuristics positively affect the pedagogical quality of e-learning software. The planned final research phase (Phase 3) of this study is to establish whether the pedagogy influences learning performance and motivation as theorized, it will further validate the findings of the first two phases by confirming them using quantitative methods and attempting to generalize them to a wider population.

\section{REFERENCES}

[1] Alonso, F., López, G., Manrique, D., \& Vines, J. (2005). An instructional model for web-based e-learning education with a blended learning process approach. British Journal of Educational Technology, 36(2), 217-235. http://dx.doi.org/10.1111/j.14678535.2005.00454.x

[2] Bell, T., Andreae, P. and Lambert, L., 2010, January. Computer science in New Zealand high schools. In Proceedings of the Twelfth Australasian Conference on Computing Education-Volume 103 (pp. 15-22). Australian Computer Society, Inc..

[3] Bessenyei, I. (2008). Learning and teaching in the information society. Elearning 2.0 and connectivism. Information Society, R.Pinter (Ed), Ed.Gondolat, 2008(9), 1-14.

[4] Brooks, J. G., \& Brooks, M. G. (1999). In Search of Understanding: The Case for Constructivist Classrooms. Alexandria, VA, USA: Association for Supervision \& Curriculum Development (ASCD).

[5] CAS. (2011). Computing at School International Comparisons. $\begin{array}{llll}\text { Retrieved } & \text { May } & 27, & \text { 2015, from }\end{array}$ http://www.computingatschool.org.uk/data/uploads/internationalcomp arisons-v5.pdf

[6] Chan, C. H., \& Robbins, L. I. (2006). E-learning systems: Promises and pitfalls. Academic Psychiatry, 30(6), 491-497. doi:10.1176/appi.ap.30.6.491

[7] Clark, R. C., \& Mayer, R. E. (2011). e-Learning and the Science of Instruction: Proven Guidelines for Consumers and Designers of Multimedia Learning, 3rd Edition: John Wiley \& Sons.

[8] Computing at Schools Working. (2012). Computer Science: A curriculum for schools. Retrieved May 27, 2015, from http://www.computingatschool.org.uk/data/uploads/ComputingCurric .pdf

[9] e-skills UK. (2012). Technology Insight 2012. Retrieved May 27, 2015, from http://www.e-skills.com/research/researchpublications/insights-reports-and-videos/technology-insights-2012/

[10] Fleming, N. D., \& Mills, C. (1992). Not another inventory, rather a catalyst for reflection. To Improve the Academy, 11, 137 - 155.

[11] Gove, M. (2012). Michael Gove gives a speech at the BETT Show 2012 on ICT in the National Curriculum. Retrieved May 27, 2015, from https://www.gov.uk/government/speeches/michael-gove-speechat-the-bett-show-2012

[12] Hadjerrouit, S. (2010). A conceptual framework for using and evaluating web-based learning resources in school education. Journal of Information Technology Education: Research, 9(1), 53-79.

[13] Halse, M. . M., Mallinson, B., \& Mallison, B. J. (2009). Investigating popular Internet applications as supporting e-learning technologies for teaching and learning with Generation Y. International Journal of Education and Development Using ICT, 5(5), 58-71.

[14] Illeris, K. (Ed.). (2009). Contemporary Theories of Learning: Learning Theorists In Their Own Words. New York: Routledge - Taylor \& Francis Group. http://dx.doi.org/10.4324/9780203870426

[15] ITU, I. T. U. (2013). Measuring the Information Society. Retrieved from D/Statistics/Pages/publications/mis2013.aspx

[16] Keller, J. (2006). Development of two measures of learner motivation. Unpublished Manuscript in Progress. Florida State ....

[17] Keller, J. M. (1987). Development and use of the ARCS model of instructional design. Journal of Instructional Development, 10(3), $2-$ 10. doi:10.1007/BF02905780

[18] Office of National Statistics. (2013). Internet Access - Households and Individuals, 2013. Retrieved May 27, 2015, from http://www.ons.gov.uk/ons/rel/rdit2/internet-access---households-andindividuals/2013/index.html

[19] Pritchard, A. (2009). Ways of learning learning theories and learning styles in the classroom (2nd ed.). Abingdon, Oxon; New York, NY: Routledge. http://dx.doi.org/10.4324/9780203887240

[20] Sun, P.-C., Tsai, R. J., Finger, G., Chen, Y.-Y., \& Yeh, D. (2008). What drives a successful e-Learning? An empirical investigation of the critical factors influencing learner satisfaction. Computers \& Education, 50(4), 1183-1202. doi:10.1016/j.compedu.2006.11.007

[21] Susman, G., \& Evered, R. (1978). An assessment of the scientific merits of action research. Administrative Science Quarterly, 23. http://dx.doi.org/10.2307/2392581

[22] The Royal Society. (2012). Shut down or restart? The way forward for computing in UK schools. Technology. Retrieved May 27, 2015, from https://royalsociety.org/education/policy/computing-in-schools/report/

[23] Vogel-Walcutt, J. J., Gebrim, J. B., Bowers, C., Carper, T. M., \& Nicholson, D. (2011). Cognitive load theory vs. constructivist approaches: which best leads to efficient, deep learning? Journal of Computer Assisted Learning, 27(2), 133-145. doi:10.1111/j.13652729.2010.00381.x

[24] Vygotsky, L., 1978. Interaction between learning and development, Available

https://scholar.google.com/scholar?q=Constructivism+and+Learning. + cobb $+1994 \&$ btnG $=\&$ hl $=$ en\&as_sdt $=0 \% 2$ C5\#1 [Accessed February 3, 2015].

[25] Reigeluth, C.M. ed., 2013. Instructional Design Theories and Models: An Overview of Their Current Status, Routledge. http://dx.doi.org/10.4324/9780203872130 